\title{
IDENTIFYING CONTEXTUAL PREDICTORS OF URBAN PARK UTILIZATION AMONG INTER-ETHNIC GROUPS IN MALAYSIA
}

\author{
Hesham Omran ELFARTAS ${ }^{1}$, Haithem Ahmed ALBEERA (D) ${ }^{2,}{ }^{*}$, Ismail SAID ${ }^{3}$, Job U. MOMOH ${ }^{4}$ \\ ${ }^{1}$ Department of Architecture and Civil Engineering, Higher Institute of Science and Technology, Al-Khoms, Libya \\ ${ }^{2}$ Department of Architectural and Urban Planning, Faculty of Engineering, Misrata University, Misrata, Libya \\ ${ }^{3}$ Department of Landscape Architecture, Faculty of Built Environment, 81310 Skudai, Johor, Malaysia \\ ${ }^{4}$ Visiting Research Fellow, School of Architecture, Design and the Built Environment, \\ Nottingham Trent University, United Kingdom
}

Received 07 December 2018; accepted 06 May 2019

\begin{abstract}
Social interaction among diverse ethnic groups motivates people within communities to visit urban parks towards achieving social cohesion. Malaysians of different ethnic backgrounds spend their leisure time in urban parks because it offers opportunities for social interaction. The perception and requirement of attributes needed varies among the various ethnic groups of Malays, Chinese and Indians in order to be assured of their full utilization of the parks. This study investigates the urban park attributes that encourage the utilization of urban park by these three ethnic groups toward achieving social cohesion. Using a survey questionnaire method a total of 274 respondents were sampled at Batu Pahat urban parks in Johor, Malaysia. Afterwards, Structural Equation Modelling (SEM) was used to analyse and validate respondents' perception of urban park utilization. The findings show that aesthetics, safety, lighting, maintenance and cleanliness in public spaces attracted people to visit the urban park and contributed towards social cohesion.
\end{abstract}

Keywords: multi-ethnicity, quality, attributes, social interaction, urban park and public spaces.

\section{Introduction}

In urban centres, public spaces are considered as places with natural space for people to access and use (Balram \& Dragicevic, 2005). Therefore they play host to people from various social and economic backgrounds within a community enabling them to spend their leisure time and interact with one another. Similarly, public spaces play a crucial role in supporting social interactions between people in every society, providing social and psychological services to urban inhabitants thereby improving the quality of life. They promote multiculturalism among people of diverse social backgrounds. Hence the distribution of public spaces and the ease to access such spaces support the social functions in the urban community (Barbosa et al., 2007). The significance of attraction to public spaces could be a good indicator of prospects of social contact among ethnic groups and neighbours which also contribute to making such places liveable and active (Golicnik \& Ward Thompson, 2010). The Agora is public space which religion, politics and administration were all gathered, considered as the heart of the Greek polis. Nowadays studies of urbanism the agora is known as the quintessential or successful public space, open space where the Athenians conducted the famous ostracisms (Dickenson, 2014). The quality of public spaces attracts people to utilize them and also promote socialization among users. The study aim is to investigate the relationship between physical attributes and utilization of public spaces and their effects on social interaction and cohesion among users in a multi-ethnic urban community in Malaysian towns. Thus, people frequently visit public spaces for social pleasure and also to engage in physical activities which differ across societies. For instance, in Australia, most people engage in passive activities in public spaces, as they prefer to be alone sometimes with one or two people. While in China, secluded fields and seating areas are absent because most Chinese parks have a large number of users especially during the weekends (Buchecker, 2009). Nevertheless, Lipton (2002) observed that public space use is part of people's daily life as it provides an avenue for them to exercise and interact with family members or friends.

*Corresponding author. E-mail: utmurbandesign@gmail.com 
Furthermore, public spaces provide relief from crowded and stressful urban routines (Chiesura, 2004; Sanesi, Lafortezza, Bonnes, \& Carrus, 2006) urbanism has had a positive effect in providing a better quality of living, whereas it has a negative effect in many other areas such as; increasing populations in the cities and town which creates slums and unplanned residential areas, environmental pollution, and other challenges (Antweiler, 2018). Thereby enabling visitors to fulfil their social, psychological and physical body needs (Jules, 2008; Engel, 2002). According to Abu Bakar (2002), the British left three historical public parks when leaving Malaysia in the middle of 1957. These parks include; Lake Garden Park in Kuala Lumpur, Penang Botanical Garden in Penang and Taiping Lake Gardens. Parallel to that, (Malek Mariapanb \& Shariffc, 2012) asserted the importance of understanding the preferences, usage patterns and needs of Malaysian recreation undertakings in these public spaces. Thus, public space typology in the urban community depicts various user needs. Lynch (1984) noted that green wedges, greenbelts, parks, plazas and playfields contribute to the typology of urban public spaces. In Malaysia, public spaces in urban centres exist in the form of parks, squares and playfields.

Against this background, this research focuses on the properties and attributes of public spaces among three ethnic groups in order to promote social interaction and cohesion in Batu Pahat town, Malaysia. The choice of the three ethnic groups of Malays, Chinese and Indians are to evaluate their level of public spaces' utilization and perception on the public spaces' attributes that attract them to the urban parks. In addition, the factors affecting the utilization of public space in Malaysia within different cultural backgrounds were investigated. Findings reveal the motives for utilizing public spaces among the three ethnic groups which include the need for socialization, quality of the public place, experiencing attractiveness and social interaction thereby generating social cohesion.

Urban public spaces are categorized based on the functions preferred by the urban community and how their leisure time is spent. According to James et al. (2009), public spaces are perceived as important parts of the neighbourhood that provide opportunities for residents to interact with the urban community. Madanpour (2010) pointed out that any public space that is defined as public, means that it should be accessible to all people, and all people have the right to be there. Urban parks and playgrounds fulfil a variety of social and psychological needs of the residents that often lead them to communicate in public spaces (Ngesan Karim, Zubir, \& Ahma, 2013). In recent times, people seem scared to utilize public spaces in the evening and at night especially when they are unfamiliar with the place and feeling unsafe to interact with other people. Therefore, people need to be encouraged by providing attractive facilities and safety measures in public spaces. Meanwhile, when public spaces become insufficient and unsatisfactory for community interaction, the recreational significance of the public space should consider users from a diverse background (Oguz, 2000).

\section{Research background}

\subsection{Significance of urban park utilization}

Public spaces significantly promote interaction between citizens from different multi-ethnic groups (Lofland, 1998; Fainstein, 2005). Appropriation of spaces can lead to more connections with urban park spaces and more opportunities for social interactions. According to Peters, Elands, and Buijs (2010), all ethnic groups' culturally feel the need to utilize public spaces for relaxation with a majority of users utilizing public space with their family members or friends. Thus, people frequently prefer to utilize public spaces in an urban community where multi-ethnic groups can be found in order to communicate with others and create social interaction with friends and neighbours (Teig et al., 2009).

Urban public spaces are categorized based on the functions preferred by the urban community and how their leisure time is spent. According to James et al. (2009), public spaces are perceived as important parts of the neighbourhood that provide opportunities for residents to interact with the urban community. Urban parks and playgrounds fulfil a variety of social and psychological needs of the residents that often lead them to communicate in public spaces (Ngesan et al., 2013). In recent times, people seem scared to utilize public spaces in the evening and at night especially when they are unfamiliar with the place and feeling unsafe to interact with other people. Therefore, people need to be encouraged by providing attractive facilities and safety measures in public spaces. Meanwhile, when public spaces become insufficient and unsatisfactory for community interaction, the recreational significance of the public space should consider users from a diverse background (Oguz, 2000).

\subsection{Social interaction in urban park}

In sociology, public space provides an avenue for social and physical interactions in a multi-ethnic society. Zhou and Rana (2012) stated that public space offers an opportunity for frequent social interactions among members of the community than other places in the urban centre. In addition, frequent social interactions promote a sense of feeling and acceptance created among individuals and groups from the diverse ethnic origin (Putnam, 2000). For social ties among members of a community to develop, people have to be able to meet to create relationships among one another (Völker et al., 2007). Social interaction is an important experience in public space utilisation (Lawson \& Liu, 2011) and it occurs within people in friendly or unfriendly ways (Easthope \& McNamara, 2013).

Consequently, the level of social interaction in a public space is partly dependent upon how it is designed. Cattell, Dinesb, Geslerc, and Curtisd (2008) believe that any design that accommodates an array of activities provide an avenue for people from various socio-cultural background to socialize with one another. The authors maintained that 
the more the series of activities a public space is provided with, the greater the chances for social interaction to take place among people from diverse backgrounds. For example, Demerath and Levinger (2003) and Hesham, Ismail, and Hisyam (2014) reported in their study that chaotic urban public spaces that have lots of activities taking place simultaneously, attract more people due to the fact that many people visit and utilize the place. It also provides ease of movement from one activity to another for users' comfort. By engaging in various activities in the public space, people spend their leisure time with others from diverse cultural backgrounds thereby building bond and trust (Swanwick, Dunnett, \& Woolley 2003; Huang, 2006; Völker, Flap, \& Lindenberg 2007).

\subsection{The concept of social cohesion}

Social cohesion could be described as a resultant effect of interaction among people that make them feel a sense of belonging to the community. However, Buckner (1988) conceptualized social cohesion as having three dimensions: first, as a sense of community, which implies the feeling of belonging to a certain group. Second, is the attraction with the neighbourhood- a force that persuades its inhabitants to continue to reside in it and third, is the social connection which is explained by the frequency of social ties among neighbours. In effect, social cohesion in a neighbourhood is created when a strong sense of belonging exists among members of the community.

According to Carr and Williams (1993), public spaces in urban centres have the ability to promote a sense of community within the neighbourhood because they can provide avenues for people to interact with their neighbours in a safe and appealing setting. For example, Shannon and Werner (2008) reported that families, particularly children were provided with the opportunities to interact with one another in a safe setting and which encouraged them to work and learn from each other. Similarly, Easthope and McNamara (2013) found that public spaces and parks are the major locations for social interaction where people easily interact within the neighbourhood. Also, Nash and Christie (2003) noted that social cohesion implies that all social groups have a sense of freedom to use public spaces, free from attack and ensures the safety of users. These are common features for effective social cohesion among visitors to public spaces.

\subsection{Significance of public space quality}

Public space is one of the urban community's strategies used in promoting the quality of life of the people (Chiesura, 2004). Shores and West (2010) noted that large public space with good environmental quality settings attracts more people than those with less environmental quality. There is a correlation between urban comfort and the existence of good environmental quality (Gómez \& Jabaloyes, 2001). The quality attribute of the public space environment enhances social interaction (Bedimo-Rung, Mowen, \& Cohen, 2005; Semenza, 2003). It also influ- ences the type of social activities people would prefer to engage in which may increase or reduce their rate of visitation (Nordh \& Ostby, 2013). Accordingly, Jorgensen Hitchmough, and Calvert (2002) assert that the quality of public space is significant in determining how residents utilise it. For example, un-kept environment and vandalism of some facilities in a public space could give the impression that it is potentially unsafe for users and thus may decrease the number of visitations (Coles \& Bussey, 2000; Williams \& Green, 2001; Barbosa et al., 2007). According to Bruse (2007), one of the important elements in urban planning is the promotion of quality of public space through the provision of facilities that will enhance social interaction and relaxation. For instance, provision of shady trees in the public spaces could encourage visitation during hot weather. Similarly, maintenance and cleanliness of public space are some of the quality attributes that people look out for in making their visitation choice. Cranz (1982) has observed that a lack of interest in public space maintenance as a major contributor to the decline in its utilization. Although these places seem to be well designed and clean and at the same time empty of people, this is an indication that there is an issue in the place, which could be in the design process or management or even in both (Peinhardt, 2017).

\section{Method}

\subsection{Site background}

Appropriately this study considered the second most developed district in Johor state, Johor Peninsular Malaysia. Batu Pahat is 240 kilometres away from the capital city Kuala Lumpur. Batu Pahat town is located at Johor that has a population of about 400,000 local residents (Kasmon Permarupan, Al-Mamun, \& Zainol, 2014). It is made up of $37.08 \%$ Malays, $60.29 \%$ Chinese, and 3\% Indians. The urban Park is the largest public space in Batu Pahat which

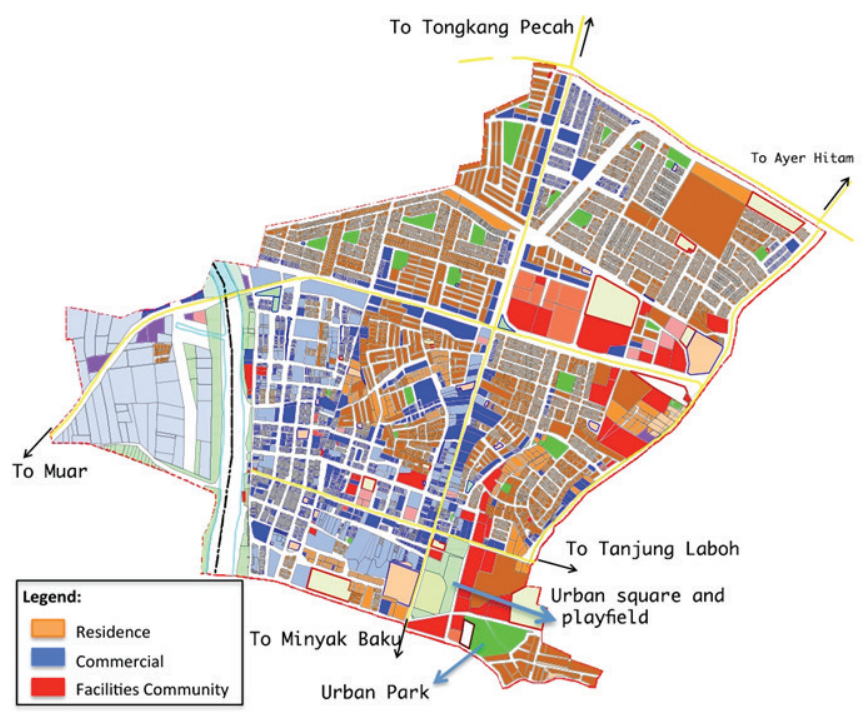

Figure 1. Main districts in Land use map of Batu Pahat (source: Majlis Perbandaran-Urban Planning Dept. Batu Pahat) 
is visited by its local residents and other people from other parts of the Batu Pahat and beyond. The researcher selected the urban park due to their unique identities with two lake and children playground. Moreover, the selected public spaces have equal access to the public and have a good visual connection with the surrounding area. As shown in Figure 1 urban park is located near the residential as well as the commercial areas, and it was selected also based on attributes such as size, green density and design characteristics which represents elements of attraction to users.

\subsection{Measures and dimensions}

The phenomenon was measured through factors of social interaction, activities, quality attributes and attributes attraction. The social interaction factor was adopted and operationalized from Holland Clark, Katz, and Peace (2007) and Wagner and Peters (2014). Social interaction refers to the engagement among diverse people and contact of these individual and group that generates unity and harmony in a community. Similarly, activity as a factor was espoused from Gehl and Gemzøe (2001) and Lawson and Liu (2010) while the factor of attributes attraction was adopted from Basri (2011) and Mansor (2011). Activities involve people's participation in social and physical performances in outdoor spaces. Meanwhile, the attributes of attraction refer to people's perception and meanings given to different places in terms of its scenic beauty. Also, the quality of public space attributes which refer to psychosocial benefits of the park was adopted from H. Tinsley, C. Tinsley, and Croskeys (2002).

Therefore, the influence of urban park attributes on interaction, attribute attraction and activities that lead to social cohesion as examined by this study, the following hypotheses were operationalized for evaluation. The conceptual relationship is thus presented in Figure 2.

H1. SIN positively influences SC.

H2. QA positively influences SC.

H3. AAT positively influences SC.

H4. ACT positively influences SC.

Where: $\mathrm{SIN}=$ Social interaction, $\mathrm{ACT}=$ Activities, $\mathrm{QA}=$ Quality Attribute, AAT $=$ Attributes attraction, $\mathrm{SC}=$ Social cohesion and $\mathrm{H}=$ Hypothesis

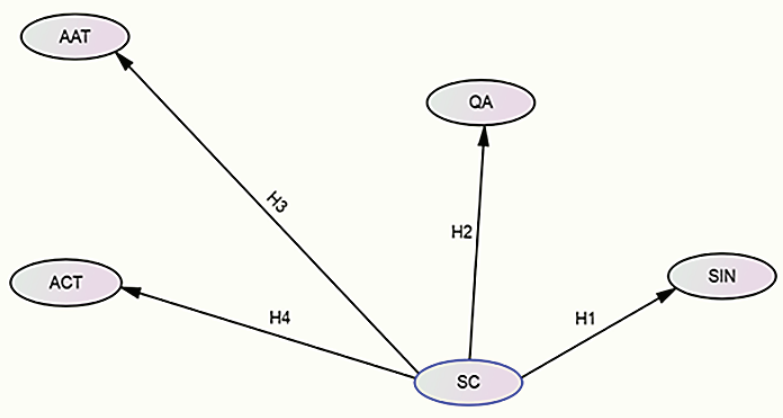

Figure 2. Proposed Research theoretical framework (source: authors)

\subsection{Research instrument and data collection from participants}

The study adopted quantitative survey method using surveys questionnaire as an instrument to obtain information from participants, In fact, the quantitative methodology been selected for this study, because of the factors that affect the utilization in public space are quantitative. A total number of 274 sets of questionnaire forms comprising of different sections were randomly distributed to elicit data from people who utilize the Urban Parks at different hours of the day, particularly during weekends. The first section consists of the demographic profile of the respondents and includes gender, age, ethnic background and occupation. The second section of the research instrument elicited data on how people utilize the urban park and those with whom they interact. The third section inquires about activities, particularly most attractive ones people engage in while utilising the urban park. Finally, the fourth section covers visitors' perception of the quality of urban park attributes that attract them to utilize the available facilities. Thereafter, the study used Structural Equation Model SEM (AMOS) to analyse the data retrieved from the questionnaire forms and documented using SPSS software.

\section{Analysis and results}

Urban park model was developed based on the hypothetical framework by subjecting the variables measured to psychometric analysis using confirmatory factor analysis (CFA) as proposed by Anderson and Gerbing (1992). Scholars have recommended a threshold for factor loading overriding the value of 0.5 with p-value 0.002 has been considered acceptable (Hair, Anderson, Tatham, \& Black 1995). The outcome values are shown in Table 1. Accordingly, Nunnally (1967) recommended an acceptable alpha of $\geq 0.50$. However, considering the use of these scales for the first time in a new culture, the cut-off value for the alpha coefficient was set at 0.60 for all the scales (self-developed scales). The validity of factors that revealed the model fitness was established and data reliability of items whose path loading were also determined. It is observed that a normalized $\mathrm{x} 2$ for the determined model has a value of $1.773(\mathrm{x} 2 / \mathrm{df}=1.773$, where $\mathrm{df}=356)$. The result is within the recommended value of less than 3.0 for normalized x2 (Bagozzi \& Yi, 1988) indicating a good outcome. Therefore, CFA was used to determine whether the number of factors and the loadings of measured items had conformed to what was expected. Items which loaded weakly on the hypothesized factors were deleted from the scale, thus resulting in a one-dimensional scale. Thus, the comparative fit index (CFI) recorded the value of 0.846 , the Non-Normed Fit Index (NNFI) recorded 0.812 which aligned with the marginal recommended and acceptable value of $\geq 0.8$ (Chau \& Hu, 2001). Next, the root means a square error of approximation (RMSEA) with a fit value of 0.053 which reliably fits the threshold range of 0.08 recommended by Browne and Cudeck (1993) which indicates a strong fit. Overall, the output of this analysis indicates that the measurement model displays a good degree of fit level and therefore acceptable as the model structure (Figure 3). 
Table 1. Measurement variance analysis and reliabilities (source: authors)

\begin{tabular}{|c|c|c|c|}
\hline Factors & Estimates & T-values & Cronbach's Alphas \\
\hline Social interaction & & & 0.554 \\
\hline Neighbour & 0.58 & 5.364 & \\
\hline Friends from the same ethnic & 0.41 & Constrained & \\
\hline Friends from different ethnic & 0.61 & 4.120 & \\
\hline Stranger & 0.39 & 3.294 & \\
\hline Family & 0.27 & 3.116 & \\
\hline Activities & & & 0.674 \\
\hline Charting among same ethnic & 0.47 & 3.497 & \\
\hline Charting among different ethnic & 0.47 & 3.324 & \\
\hline Taking photo & 0.45 & 3.299 & \\
\hline Exercise & 0.34 & 3.005 & \\
\hline Picnic & 0.69 & 3.553 & \\
\hline Recreational activities & 0.57 & 3.623 & \\
\hline Leisure activities & 0.27 & Constrained & \\
\hline Attribute attraction & & & 0.670 \\
\hline Aesthetics & 0.72 & Constrained & \\
\hline Social activities & 0.52 & 7.258 & \\
\hline Seating & 0.64 & 8.443 & \\
\hline Quality of Track & 0.55 & 7.124 & \\
\hline Water elements & 0.64 & 8.181 & \\
\hline Tree Shades & 0.57 & 7.488 & \\
\hline Quality attribute & & & 0.708 \\
\hline Maintenance & 0.65 & Constrained & \\
\hline Quality of trees & 0.41 & 5.739 & \\
\hline Facilities & 0.68 & 9.327 & \\
\hline Cleanliness & 0.75 & 10.20 & \\
\hline Safety & 0.73 & 10.05 & \\
\hline Size & 0.61 & 8.541 & \\
\hline Quietness & 0.30 & 4.372 & \\
\hline Harmony & 0.77 & 9.693 & \\
\hline Social Cohesion & & & 0.468 \\
\hline Social cohesion 1 & 0.20 & Constrained & \\
\hline Social cohesion 2 & 0.29 & 4.399 & \\
\hline Social cohesion 3 & 0.33 & 4.373 & \\
\hline
\end{tabular}

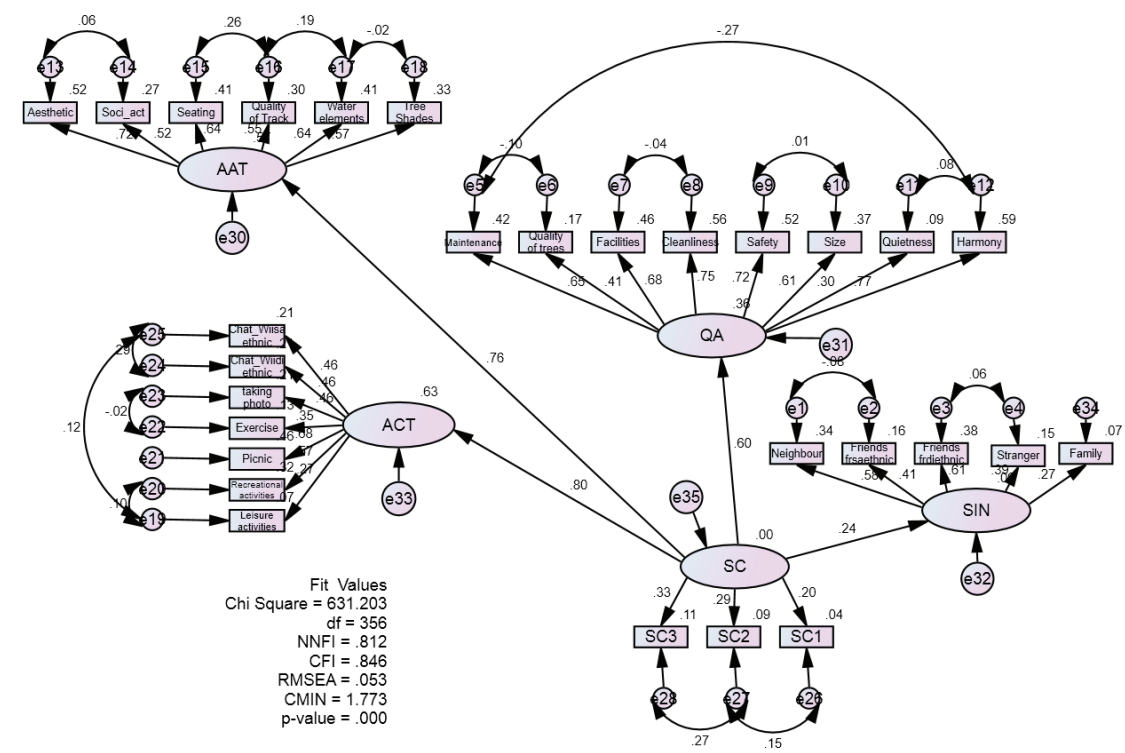

Figure 3. Confirmatory analysis model of urban park utilization in relation to social cohesion (source: authors) 
Table 2. Summary of the results structural model (source: authors)

\begin{tabular}{|c|l|c|c|}
\hline Hypothesis & \multicolumn{1}{|c|}{ Hypothesized path } & Path coefficient & Results \\
\hline H1 & SIN can positively influence social cohesion in urban park utilisation & 0.24 & Supported \\
\hline H2 & QA can positively influence social cohesion in urban park utilisation & 0.60 & Supported \\
\hline H3 & AAT can positively influence social cohesion in urban park utilisation & 0.76 & Supported \\
\hline H4 & ACT can positively influence social cohesion in urban park utilisation & 0.80 & Supported \\
\hline
\end{tabular}

\section{Discusion}

The measured factors of urban park utilization which includes activities, social interaction, attributes attraction and quality attributes aimed towards achieving social cohesion exhibited different path loadings. The finding suggests that these factors influenced social cohesion on urban park utilization which was accessed via the Hypotheses $\mathrm{H} 1$ to $\mathrm{H} 4$ as shown in Figure 2. Path loadings threshold as shown in Table 2 is above 0.2 which is accepted as significant loading (Cohen, 1988, 1992a, 1992b). Overall, social activities and attributes' attraction showed the strongest influence on urban park utilization to social cohesion. The SEM (AMOS) result output of the confirmatory model showed strong and reliable path loadings for the factors as presented in Figure 3. The result shows almost all measuring constructs of urban park utilization having path loadings that ranged from 0.24 to 0.80 on social cohesion. Urban park utilisation showed path loading of 0.80 on activities and 0.76 on attributes attraction. Thus, activities and attributes attraction had stronger path loadings compared to other factors on park utilization. It, therefore, implies that urban park utilisation effectively reflects activities that attract these multi-ethnic groups to utilise the urban park and promote social interaction while achieving cohesion when they engage in park activities. The hypotheses $\mathrm{H} 1, \mathrm{H} 2, \mathrm{H} 3$ and $\mathrm{H} 4$ were thus supported by this analysis. For instance, interactions among families and friends of the same ethnic group are improved when they perform activities together within the park. However, low attraction and participation are often witnessed as a result of the non-availability of ethnic activities.

In addition, users indicated that water elements which include the two lakes and trees that are located in the urban park provide aesthetics, and are elements that attract them to the park. Accordingly, people are attracted to sit under the trees as they move along the lake. It, therefore, serves as a recreation point of attraction for relaxation and sharing of experiences among the urban park users. Furthermore, the urban park greenery aesthetically attracts other people to feel and associate with the natural environment. Thus, the quality of urban park attributes such as tree shades, shelters, security and safety, cleanliness, comfortable surroundings, park size, good and wellmaintained facilities for physical activities influences the way people are attracted and utilize the urban park.

The outcome affirms that the multi-ethnic community utilize urban park with preference to engaging in various activities, thus a significant factor in influencing people to utilize the urban park and promoting social cohesion among them. This finding is consistent with Goudarzi (2013) who found that people are attracted to utilize public space based on available activities that support social interactions. This means that these activities allow them to interact with one another thereby ensuring social cohesion. In addition, this finding appears to also agree with Cradock, Kawachi, Colditz, Gortmaker, and Buka (2009) who suggested that social cohesion increases with increase in the frequency of engagement in physical and social activities such as exercise, jogging, walking and football or other forms of activities in an urban park. It means that the more attracted an individual is to a group the more he engages in activities with the group, also the higher the possibility for social cohesion to occur. In addition, the outcome aligns with Gilliland, Holmes, Irwin, and Tucker (2006) who indicated that the quality of park attributes are significant in attracting users to engage in urban park activities. It implies that urban park attributes influences people decision on urban park utilisation which determines the occurrence of social cohesion among the users. In sum, it means that both activities and quality of attributes are significance in supporting multi-ethnic interaction and promoting social cohesion and satisfaction among people.

\section{Conclusions}

This study discovered the nature of urban park utilization in Batu Pahat town, Malaysia to have created a platform of social cohesion among the diverse cultures. Thus, an essential facility for creating social cohesion among users whose designs and management should take into account leisure requirements that provides and attracts residents' to visit the urban park. Significantly the outcome shows the effect of ethnic diversity in promoting urban park utilization towards common understanding among multi-ethnic groups. This was achieved from the physical attributes and people's interaction as they utilize the urban park. So, urban park utilisation encouraged exchange and sharing of life experiences which led to greater socialising among neighbours and friends. Afterwards social value through interacting with family and making new friends shows users' satisfaction in urban park engagements. Urban park planning and maintenance should, therefore, account for multi-ethnic communities' needs by providing essential and quality facilities that are key in connecting people together. 


\section{References}

Abu Bakar, J. (2002). A design guide for public parks in Malaysia. Skudai. Penerbit Universiti Teknologi Malaysia.

Anderson, J. C., \& Gerbing, D. (1992). Assumptions of the twostep approach to latent variable modelling. Sociological Methods and Research, 20(3), 321-333.

https://doi.org/10.1177/0049124192020003002

Antweiler, C. (2018). Urbanization and urban environments. In The International Encyclopedia of Anthropology (pp. 1-10). Oxford, UK: John Wiley \& Sons, Ltd. Retrieved from http:// doi.wiley.com/10.1002/9781118924396.wbiea1585

Bagozzi, R. P., \& Yi, Y. (1988). On the evaluation of structural equation models. Journal of the Academy of Marketing Science, 16(1), 74-94. https://doi.org/10.1007/BF02723327

Balram, S., \& Dragićević, S. (2005). Attitudes toward urban green spaces: integrating questionnaire survey and collaborative GIS techniques to improve attitude measurements. Landscape and Urban Planning, 71(2), 147-162.

https://doi.org/10.1016/S0169-2046(04)00052-0

Barbosa, O., Tratalos, J. A., Armsworth, P. R., Davies, R. G., Fuller, R. A., Johnson, P., \& Gaston, K. J. (2007). Who benefits from access to green space? A case study from Sheffield, UK. Landscape and Urban Planning, 83(2), 187-195. https://doi.org/10.1016/j.landurbplan.2007.04.004

Basri, B. H. (2011). Valuing the attributes of Malaysian recreational parks: a choice experiment approach (Doctoral dissertation). School of Agriculture,(Newcastle University).

Bedimo-Rung, A. L., Mowen, A. J., \& Cohen, D. A. (2005). The significance of parks to physical activity and public health: a conceptual model. American Journal of Preventive Medicine, 28(2, Supplement 2).

https://doi.org/10.1016/j.amepre.2004.10.024

Browne, M. W., \& Cudeck, R. (1993). Alternative ways of assessing model fit. Sage, Newbury Park, CA.

Bruse, M. (2007). Simulating human thermal comfort and resulting usage patterns of urban open spaces with a Multi- Agent System. Proceedings of the 24th International Conference on Passive and Low Energy Architecture PLEA (pp. 699-706).

Buchecker, M. (2009). Withdrawal from the local public place: Understanding the process of spatial alienation. Landscape Research, 34(3), 279-297.

https://doi.org/10.1080/01426390902867968

Buckner, J. C. (1988). The development of an instrument to measure neighborhood cohesion. American Journal of Community Psychology, 16(6), 771-791.

https://doi.org/10.1007/BF00930892

Carr, D. S., \& Williams, D. R. (1993). Understanding the role of ethnicity in outdoor recreation experiences. Journal of Leisure Research, 25, 22-38.

https://doi.org/10.1080/00222216.1993.11969907

Cattella, V., Dinesb, N., Geslerc, W., \& Curtisd, S. (2008). Mingling, observing, and lingering: Everyday public spaces and their implications for well-being and social relations. Health \& Place, 14(2008), 544-561. https://doi.org/10.1016/j.healthplace.2007.10.007

Chau, P. Y. K., \& Hu, P. J.-H. (2001). Information technology acceptance by individual professional: A model comparison approach. Decision Sciences, 32(4), 699-719. https://doi.org/10.1111/j.1540-5915.2001.tb00978.x

Chiesura, A. (2004). The role of urban parks for the sustainable city. Landscape and Urban Planning, 68(1) (May), 129-138. https://doi.org/10.1016/j.landurbplan.2003.08.003
Cohen, J. (1988). Statistical power analysis for the behavioral sciences (2nd ed.). Lawrence Erlbaum Associates. Hillsdale, NJ.

Cohen, J. (1992a). A power primer. Psychological bulletin, 112(1), 155. https://doi.org/10.1037//0033-2909.112.1.155

Cohen, J. (1992b). Statistical power analysis. Current directions in psychological. Current directions in psychological science, 98-101. https://doi.org/10.1111/1467-8721.ep10768783

Coles, R. W., \& Bussey, S. C. (2000). Urban forest landscapes in the UK - progressing the social agenda. Landscape and Urban Planning, 52, 181-188. https://doi.org/10.1016/S0169-2046(00)00132-8

Cradock, L., A., Kawachi, I., Colditz, G. A., Gortmaker, S. L., \& Buka, S. L. (2009). Neighborhood social cohesion and youth participation in physical activity in Chicago. Social Science \& Medicine, 68, 427-435.

https://doi.org/10.1016/j.socscimed.2008.10.028

Cranz, G. (1982). The politics of park design. A history of urban

parks in America. The MIT Press.

Dickenson, C. P. (2014). Looking at public space - the Greek agora in Hellenistic and Roman times. Groniek, 198(198), 85-95.

Demerath, L., \& Levinger, D. (2003). The social qualities of being on foot: a theoretical analysis of pedestrian activity, community, and culture. City \& Community, 2(3), 217-237. https://doi.org/10.1111/1540-6040.00052

Easthope, H., \& McNamara, N. (2013). Measuring social interaction and social cohesion in a high density urban renewal area: the case of Green Square. City Futures Research Centre, University of New South Wales.

Engel, L. J. (2002). Saul D. Alinsky and the Chicago school. Journal of Speculative Philosophy, 16, 50e66. https://doi.org/10.1353/jsp.2002.0002

Fainstein, S. S. (2005). Cities and diversity. Urban Affairs Review, 41(1), 3-19. https://doi.org/10.1177/1078087405278968

Gehl, J., \& Gemzøe, L. (2001 ). New city spaces. Copenhagen: The Danish Architectural Press.

Gilliland, J., Holmes, M., Irwin, J. D., \& Tucker, P. (2006). Environmental equity is child's play: mapping public provision of recreation opportunities in urban neighbourhoods. Taylor \& Francis Group, Vulnerable Children and Youth Studies, 1(3), 256-268. https://doi.org/10.1080/17450120600914522

Golicnik, B., \& Ward Thompson, C. (2010). Emerging relationships between design and use of urban park spaces. Landscape and Urban Planning, 94, 38-53.

https://doi.org/10.1016/j.landurbplan.2009.07.016

Gómez, F., Tamarit, N., \& Jabaloyes, J. (2001). Green zones, bioclimatics studies and human comfort in the future development of urban planning. Landscape and Urban Planning, 55(3), 151-161. https://doi.org/10.1016/S0169-2046(01)00150-5

Goudarzi, M. (2013). The role of public participation on developing urban park. Journal of Academic and Applied Studies (Special Issue on Applied Sciences), 3(9) September 2013, 13-21.

Hair, J. F., Anderson, R. E., Tatham, R. L., \& Black, W. C. (1995). Multivariate data analysis with readings (4th ed.). Englewood Cliffs, NJ: Prentice Hall.

Hesham, E. O., Ismail, S., \& Hisyam, R. M. (2014). Residents' perception towards social interaction among Malaysian ethnic groups in urban park. In Recent Trends in Social and Behaviour Sciences: Proceedings of the International Congress on Interdisciplinary Behaviour and Social Sciences 2013 (p. 9). CRC Press. https://doi.org/10.1201/b16658-4

Holland, C., Clark, A., Katz, J., \& Peace, S. (2007). Social interactions in urban public places. Policy Press. 
Huang, S.-C. L. (2006). A study of outdoor interactional spaces in high- rise housing. Landscape and Urban Planning, 78(3) (November), 193-204. https://doi.org/10.1016/j.landurbplan.2005.07.008

James, P., Jamesa, P., Tzoulasa, K., Adamsb, M. D., Barberc, A., Boxd, J., Breustee, J., Elmqvistf, T., Frithg, M., Gordonh, C., Greeningi, K. L., Handleyj, J., Haworthk, S., Kazmierczaka, A. E., Johnstonl, M., Korpelam, K., Morettin, M., Niemeläo, J., Pauleitp, S., Roeq, M. H., Sadlerr, J. P., \& Thompsons, C. W. (2009). Towards an integrated understanding of green space in the European built environment. Urban Forestry and Urban Greening, 8(2) 65-75.

https://doi.org/10.1016/j.ufug.2009.02.001

Jorgensen, A., Hitchmough, J., \& Calvert, T. (2002). Woodland spaces and edges: their impact on perception of safety and preference. Landscape and Urban Planning, 60(3), 135-150. https://doi.org/10.1016/S0169-2046(02)00052-X

Jules, R. (2008). Streets as places. National endowment for the arts American Conservation Association The Laura Jane Musser Fund Surdna Foundation, Inc. ISBN 978-0-97063245-6, AARP D19126.

Kasmon, N. B., Permarupan, P. Y., Al-Mamun, A., \& Zainol, N. R. B. (2014). Examining the association between consumer satisfaction, complain handling and loyalty programs with consumer loyalty towards hypermarket in Batu Pahat, Johor, Malaysia. International Business and Management, 8(1), 15-19.

Lawson, G., \& Liu, B. (2011, 11-16 April). Social interactions in Chinese Parks: a walk in Lu Xun Park. International Congress 2010 Healthy Parks Healthy People. Melbourne, Vic.

Lipton, S. (2002). The value of public space, Foreword, York. CABE Space, London.

Lofland, L. H. (1998). The public realm: exploring the city's quintessential social territory. New York: Aldine de Gruyter.

Lynch, K. (1984). Good city form. MIT Press.

Madanipour, A. (2010). Whose public space? International case studies in urban design and development (p. 8) Routledge. https://doi.org/10.4324/9780203860946

Maleka, N. A., Mariapanb, M., \& Shariffc, M. K. M. (2012). The making of a quality neighbourhood park: a path model approach. Procedia-Social and Behavioral Sciences, 49, 202-214. https://doi.org/10.1016/j.sbspro.2012.07.019

Mansor, M. B. (2011). Experiential contacts of residents with green infrastructure network in Taiping (Doctoral dissertation). Universiti Teknologi Malaysia, Faculty of Built Environment.

Nash, V., \& Christie, I. (2003). Making sense of community (Vol. Ippr) London, Institute for Public Policy Research.

Ngesan, M. R., Karim, H. A., Zubir, S. S., \& Ahma, P. (2013). Urban community perception on nighttime leisure activities in improving public park design. Social and Behavioral Sciences, 105, 619-631. https://doi.org/10.1016/j.sbspro.2013.11.065

Nordh, H., \& Østby, K. (2013). Pocket parks for people - a study of park design and use. Urban Forestry and Urban Greening 12 (2013), 12-17. https://doi.org/10.1016/j.ufug.2012.11.003

Nunnally, J. C. (1967). Psychometric theory. New York: McGrawHill.
Oguz, D. (2000). User surveys of Ankara's urban parks. Landscape and Urban Planning, 52, 165-171. https://doi.org/10.1016/S0169-2046(00)00130-4

Peinhardt, K., 2017. Still waiting for a nice place to sit. Project for Public Space. Retrieved from https://www.pps.org/article/ still-waiting-nice-place-sit

Peters, K., Elands, B., \& Buijs, A. (2010). Social interactions in urban parks: stimulating social cohesion? Urban Forestry \& Urban Greening, 9(2) (January), 93-100. https://doi.org/10.1016/j.ufug.2009.11.003

Putnam, R. D. (2000). Bowling alone: the collapse and revival of American community. New York, NY, USA: Simon and Schuster. https://doi.org/10.1145/358916.361990

Sanesi, G., Lafortezza, R., Bonnes, M., \& Carrus, G. (2006). Comparison of two different approaches for assessing the psychological and social dimensions of Green Spaces. Urban Forestry \& Urban Greening, 5(3) (October), 121-129. https://doi.org/10.1016/j.ufug.2006.06.001

Semenza, J. (2003). The intersection of urban planning, art, and public health: The Sunnyside Piazza. American Journal of Public Health, 93, 1439. https://doi.org/10.2105/AJPH.93.9.1439

Shannon, S, C., \& Werner, T. L. (2008). The opening of a municipal skate park: exploring the influence on youth skateboarders' experiences. Journal of Park and Recreation Administration, 26(3) (2008), 42.

Shores, K. A., \& West, S. T. (2010). Rural and urban park visits and park-based physical activity. Preventive medicine, 50, S13S17. https://doi.org/10.1016/j.ypmed.2009.07.023

Swanwick, C., Dunnett, N., \& Woolley, H. (2003). Nature role and value of green space in towns and cities. An overview of Built Environment, 29, 94-106.

https://doi.org/10.2148/benv.29.2.94.54467

Teig, E., Amulya, J., Bardwell, L., Buchenau, M., Marshall, J. A., \& Litt, J. S. (2009). Collective efficacy in Denver, Colorado: Strengthening neighborhoods and health through community gardens. Health \& Place, 15(2009), 1115-1122. https://doi.org/10.1016/j.healthplace.2009.06.003

Tinsley, H., Tinsley, C. \& Croskeys, C. (2002). Park usage, social milieu, and psychosocial benefits of park use reported by older urban park users from four ethnic groups. Leisure Sciences, 24, 199-218. https://doi.org/10.1080/01490400252900158

Völker, B., Flap, H. D., \& Lindenberg, S. (2007). When are neighbourhoods commu- nities? Community in Dutch neighbourhoods. European Sociological Review, 23(1), 99-114. https://doi.org/10.1093/esr/jcl022

Wagner, L., \& Peters, K. (2014). Feeling at home in public: diasporic Moroccan women negotiating leisure in Morocco and the Netherlands. Gender, Place \& Culture, 21(4), 415-430. https://doi.org/10.1080/0966369X.2013.793658

Williams, K., \& Green, S. (2001). Literature review of public space and local environments for the cross cutting review. Department for Transport, Local Government and the Regions.

Zhou, X., \& Rana, M. M. P. (2012). Social benefits of urban green space: A conceptual framework of valuation and accessibility measurements. Management of Environmental Quality: An International Journal, 23(2), 173-189. 